\title{
De la hermenéutica histórica a la hermenéutica negativa en Ignacio Ellacuría
}

\author{
Dr. Ulises Salomón Amaya ${ }^{1}$
}

Recibido: 27 de enero de 2019 - Aceptado: 1 de abril de 2019

\begin{abstract}
Resumen
La intención de este artículo es proponer la negatividad como clave de lectura y comprensión de la hermenéutica histórica de Ignacio Ellacuría. Para ello, daremos una breve explicación de la hermenéutica histórica y, posteriormente, mostraremos el carácter operativo que la negatividad tiene en los momentos de dicho ejercicio hermenéutico.
\end{abstract}

Palabras clave: negación - negatividad histórica - historización - hermenéutica - lugar-que-da-verdad

\section{From historical hermeneutics to negative hermeneutics in Ignacio Ellacuría}

\begin{abstract}
The intention of this article is to propose negativity as the key for reading and understanding the historical hermeneutics of Ignacio Ellacuría. For this, we will provide a brief explanation of historical hermeneutics, followed by a display of the operative nature of negativity in the exercise of hermeneutics.
\end{abstract}

Key words: negation - historical negativity - historization - hermeneutics place-that-gives-truth

1 Salvadoreño, Doctor en Filosofía por la Pontificia Universidad Católica de Valparaíso, Chile. Académico del Instituto de Filosofía de la Universidad de Antioquia, Medellín, Colombia. Contacto: ulises.amaya@udea.edu.co

ORCID: https://orcid.org/0000-0002-3361-4207 


\title{
Da hermenêutica histórica à hermenêutica negativa em Ignacio Ellacuría
}

\begin{abstract}
Resumo
A intenção deste artigo é propor a negatividade como chave de leitura e compreensão da hermenêutica histórica de Ignacio Ellacuría. Para aquilo, daremos uma breve explicação da hermenêutica histórica e, posteriormente, mostraremos o carácter operativo que a negatividade tem nos momentos de dito exercício hermenêutico.
\end{abstract}

Palavras-chave: negação - negatividade histórica - historização - hermenêutica - lugar-que-dá-verdade

\section{Introducción}

El presente trabajo muestra un nuevo modo de comprensión de la propuesta filosófica de Ignacio Ellacuría. Para ello, partimos de la consideración de la negatividad como un concepto operativo transversal a la obra ellacuriana y situamos nuestra reflexión en artículos y esquemas de clase de los años setenta y ochenta, tiempo que coincide con la agudización del conflicto armado salvadoreño, textos y esquemas que nos permiten comprender el lugar central que la negatividad, en su expresión histórica-real, tendrá en el desarrollo filosófico ellacuriano de esa época, no solo como aquello que se constata en la realidad histórica, sino también por el carácter operativo que tendrá en el ejercicio interpretativo de esa negatividad histórica. De esta manera, para nuestra lectura, la comprensión de la negatividad resulta clave para comprender el planteamiento ellacuriano de los años setenta y ochenta. Al explicitar el lugar de la negatividad en el ejercicio hermenéutico ellacuriano se pondrá de manifiesto un nuevo modo de aproximación a su obra. Así, la intención de este artículo consiste en la presentación de este nuevo modo de aproximación.

Nuestra investigación parte de la asunción de tres influencias teóricas que poseen una importancia operativa fundamental en la obra ellacuriana, las dos primeras en términos estrictamente filosóficos, Marx y Zubiri, y la tercera en términos teológicos, Karl Rahner. Aunque la 
pretensión de este artículo no es ahondar en dichas influencias, es pertinente señalar algunos elementos de la influencia rahneriana, ello debido a que nuestro trabajo asume la unidad de la reflexión filosófica y teológica en Ellacuría y, por ende, de la presencia de la negatividad en ambos lugares de reflexión; ello significa que ambas, filosofía y teología, nos aportan elementos para comprender su operatividad. Un elemento relevante que debe señalarse es que la comprensión y el interés en la unidad de la historia y esta como el lugar del acontecimiento de la autocomunicación de Dios con el ser humano, y por lo tanto, su irrupción histórica (Rahner 1963), además del interés por la historicidad no le llega primariamente a Ellacuría de su contacto con Zubiri, sino por la teología de Karl Rahner (Maier 1996).

La teología trascendental de Rahner es una teología que vuelve sobre el sujeto, de ahí su carácter trascendental, para así obtener una aproximación hermenéutica del mundo y de la vida. Es una teología que se afinca en la narrativa de las experiencias religiosas personales, elevando con ello al sujeto a un estatus dogmático teológico; por esta razón, este tipo de teología debe ser llamada "teología histórico-vital" (cf. Metz 229). La idea de "sujeto" no refiere a la subjetividad de la modernidad; se trata de un "sujeto histórico", un "sujeto" que deberá habérselas con sus propias situaciones, decisiones, y vivencias que lo van configurando constantemente. Así, en este tipo de planteamiento teológico asistimos a un intento de armonización histórico-vital de teoría y praxis (Ibíd.). La reflexión teológica parte de esta manera de las situaciones "mundanas" del sujeto, sin recurrir a experiencias o ideas trascedentes ahistóricas y meramente especulativas. El punto de partida de la reflexión es la vida, la vida concreta de un sujeto inmerso en la cotidianidad y cuyas vivencias son objeto de reflexión teológica. Es importante señalar que los paradigmas teológicos de ambos autores obedecen al momento histórico-biográfico de cada uno de ellos. El contexto al que responde Rahner es un mundo escéptico y ateo; el contexto ellacuriano, por su lado, está marcado por la negatividad. Se trata de una "realidad negada que no puede llegar a ser aquello que podría y debería ser porque se lo impiden" (Ellacuría 2001 a 438); sin embargo, los planteamientos rahnerianos despertarán el interés y preocupación del filósofo mártir, tal como se mencionó, 
en un nuevo modo de habérselas con la historia. El encuentro con Rahner fue fundamental para Ellacuría; pero no fue esta su primera aproximación a la historicidad: ya en la década de los sesenta había tenido algunos acercamientos a través de la filosofía de Ortega y Gasset (Ellacuría 199615 45); sin embargo, los conceptos operativos que se encuentran directamente relacionados con lo que el Ellacuría maduro comprende como "historia" e "historicidad" tienen como antecedente directo, pero no el único, a la teología de Karl Rahner. Así, en Ellacuría el ejercicio hermenéutico histórico no será un ejercicio privativo de la esfera filosófica, ya que es desde la filosofía y la teología que dicho ejercicio adquiere sentido.

\section{La hermenéutica histórica}

Uno de los mayores conocedores de la obra de Ignacio Ellacuría es Héctor Samour. Él es el responsable de la sistematización de la obra del filósofo mártir y uno de los autores que más ha contribuido al conocimiento de la obra ellacuriana. Para Samour, la hermenéutica histórica de Ellacuría posee una finalidad muy concreta, cuyo ejercicio tendrá una resonancia histórica muy clara. Se trata, sostiene Samour, de impulsar y sustentar proyectos de transformación y emancipación política (cf. Samour 2014 194) frente a la negatividad histórica. Una hermenéutica cuyo ejercicio interpretativo se da en una doble vía: hacia la intencionalidad del sujeto y hacia la constitución del objeto, por ello es una hermenéutica en la cual los elementos que participan en el ejercicio hermenéutico se ven atravesados por una nota histórica, es decir, tanto el objeto de interpretación como aquel que interpreta son radicalmente y constitutivamente históricos; de ahí que el sujeto interpretante no pueda abstraerse de aquello que motiva su ejercicio interpretativo, es decir, no existe una separación sujeto-objeto. El sujeto está involucrado históricamente con aquello que interpreta, por eso lo que interesa a Ellacuría son las condiciones históricas que posibilitan dichos objetos a interpretar. Ellacuría va a las condiciones históricas mismas, y al ir a esas condiciones se encuentra, dirá Samour, en el plano histórico-epocal real. Y precisamente por dicho carácter es que se trata de una hermenéutica fáctica, no solo 
en el sentido que va a lo fáctico, sino también, que parte de esa facticidad. Dicho en otros términos, se trata de una hermenéutica que parte de una separación metodológica de lo real, pero no de una separación realmente real, porque ésta no existe. Esto implica que en ese ejercicio hermenéutico al ser humano le va también su facticidad, es decir, su carácter de real, de ahí que no busque, según Samour, un sentido de la realidad, sino su subversión radical, porque no es el sentido lo que funda la realidad, sino la realidad la que funda a aquel.

[...] la hermenéutica que se debe utilizar no es sólo ni primariamente una hermenéutica del sentido, por más que se vivencie este sentido, sino una hermenéutica realista, que tiene en cuenta lo que toda acción y toda interpretación debe a las condiciones reales de una sociedad y a los intereses sociales que la sustenta. $Y$ esto en el caso de lo interpretado como en el caso del interpretador (Ellacuría $2000200)$.

De ahí que Ellacuría afirme que la circularidad a la cual debe prestársele atención primariamente es real histórica y social (Id. 215). Lo primario no es un horizonte teórico-discursivo sino "...un horizonte teórico-práctico y de unas realidades estructurales socio-históricas, que fluyen desde aquel y también lo reconforman..." (Ibíd.). Y es que el ser humano se encuentra en una unidad estructural con su mundo circundante, mundo que ha devenido histórico; por ello, el sentido solo es posible si parte de una praxis histórica concreta que no busque exclusivamente la interpretación de las cosas, sino su transformación histórica. En consecuencia, la hermenéutica histórica ellacuriana no busca un significado del acontecer histórico, es decir, no trata de una comprensión de la historia como un relato histórico, sino de dar cuenta de una realidad que ha devenido histórica y en la cual todas las realidades, incluyendo el ser humano, convergen y dan de sí (Samour 2014 196). Esto refiere a una comprensión de la historia como una praxis, es decir, como un proceso real histórico (Ellacuría 2000 199); por lo tanto, la hermenéutica histórica ellacuriana no busca, primariamente, una interpretación del sentido o del significado, sino una 
transformación de las condiciones sociohistóricas que la posibilitan, se trata, en definitiva, de subvertir la realidad histórica.

[...] esta hermenéutica [...] consistirá básicamente en ir a la historia entendida en su carácter formal de praxis para dilucidar críticamente el sentido expresado en las interpretaciones y en los discursos que legitiman las relaciones de poder y dominación, desenmascarando su pretendida universalidad y poniendo en evidencia las condiciones reales y los intereses sociales que la sustentan (Samour 2014 197).

\section{La negatividad y la historia}

De lo dicho hasta aquí podemos considerar que hay algunos elementos fundamentales para comprender la hermenéutica ellacuriana, a saber: historicidad, interpretación, y negación, porque se trata de negar esa realidad negada que se manifiesta en una serie de condiciones sociohistóricas que posibilitan la imposición de ciertos discursos hegemonizantes. Sin embargo, esta negatividad no es un elemento más, sino el elemento fundamental para comprender la hermenéutica histórica ellacuriana, ello a pesar de que, en unos apuntes inéditos de clase de un curso impartido de marzo a junio de 1989, el año de su asesinato, titulado "El mal común y los derechos humanos", afirme que es el mal común lo que en realidad se da, y que dicho mal configuraría la sociedad y los dinamismos que en ella operan. Según Ellacuría, frente a este mal común, cuando cobra las características de injusticia estructural y de injusticia institucionalizada, surge el problema del bien común como exigencia negadora de ese mal común, transparentado como injusticia estructural e institucional. En este sentido Samour plantea:

El mal común no es, por tanto, un concepto marginal. Es un concepto central o, mejor dicho todavía, es el término que expresa el contraste histórico decisivo para Ignacio Ellacuría, a saber, el contraste entre la negatividad de la realidad generada por la actual estructuración de la realidad histórica y la realidad que debería ser, prevista desde un horizonte de plena posibilidad (Samour 2013 7). 
Sin embargo, nos parece, si bien el mal común es un concepto fundamental, no es primario en el ejercicio hermenéutico. Lo primario es la negatividad que se constata en el enfrentamiento con esa realidad, de ahí que sea calificada como una realidad negada. El mal común es producto de un ejercicio hermenéutico negativo, de allí que dicho concepto sea lo interpretado, pero no el objeto de interpretación. En lo que sigue trataremos de dar cuenta de esa negatividad constitutiva del ejercicio hermenéutico ellacuriano. La negatividad constituye un concepto nodal para ciertos aspectos del pensamiento ellacuriano. Esta debe menos a la influencia zubiriana -para Zubiri, la realidad es lo que es, y en eso que es, es que se agota toda su realidad; así, para Zubiri, la negatividad es un momento conceptual de la realidad, pero no es constitutivo de la realidad física misma (Luengo Rubalcaba 1998 140)- que, al diálogo, explícito e implícito, con Hegel y Marx.

Es innegable el diálogo constante que Ellacuría sostuvo desde finales de los años sesenta con Hegel y Marx². Dicho diálogo se acentuó a mediados de los setenta. Para la década de los ochenta, la presencia de ellos, especialmente de Marx, será fundamental en el desarrollo de sus planteamientos. Nuestro trabajo no pretende abordar el diálogo con Hegel y Marx; sin embargo, hay ciertos elementos que nos parece pertinente señalar. Si bien se puede ver ya, a finales de la década de 1970, la utilización de ciertas categorías de origen marxista y cierta influencia hegeliana, no es sino hasta la elaboración de Filosofía de la realidad histórica que Ellacuría deja ver las razones de su aproximación a dichos autores. Para Ellacuría, tanto Hegel como Marx han comprendido la historia como aquel lugar donde la realidad da más de sí, es decir, donde la realidad alcanza un mayor nivel de densidad.

\footnotetext{
2 Véase por ejemplo el esquema sobre la "Visión sociológica del hombre latinoamericano" de 1968 del archivo personal de Ignacio Ellacuría, carpeta 1, unidad de instalación C2. En dicho esquema Ellacuría utiliza la categoría marxista de «proletario» y ya en una época tan temprana de su pensamiento puede verse el modo cómo Ellacuría historiza los conceptos, ya que no habla del proletario en términos eminentemente abstractos. Ellacuría utiliza el término partiendo de una «situación» determinada, a saber, la latinoamericana.
} 
[...] ambos autores cada uno a su manera, entienden que el objeto de la filosofía es realmente uno solo por la sencilla razón que la realidad toda forma una sola unidad y que la filosofía no es sino la conceptuación racional y totalizante de esa unidad de realidad que es ya en sí misma una unidad real y no puramente conceptual (Ellacuría 2007 18).

De esta manera, tanto Hegel como Marx estarían próximos a los planteamientos zubirianos que Ellacuría ha llamado "realismo materialista abierto", y es que, a pesar de los caminos diferentes entre ambos autores, hay algo esencial en lo que coinciden, a saber, la comprensión de la realidad como una totalidad con diversos caracteres: sistematicidad, dinamicidad y una verdad más allá de las apariencias (Ibíd.). Además, Zubiri mostró un claro interés en la filosofía de Hegel, a quien consideraba como la cumbre de la filosofía moderna, para Ellacuría uno de los grandes méritos de Hegel habría sido elevar la historia a un problema metafísico, esto como consecuencia de la afirmación hegeliana que al ser le compete, de modo intrínseco, la historicidad (Ellacuría 2009 42), y que la realidad no es solo algo natural y biológico, sino también histórico. La historia de esta manera se convierte en algo fundamental, no solo para la realidad humana, sino para aquello que deja de ser entendido como mera naturaleza, a saber, la realidad. En Hegel, dirá Ellacuría, la historia entra a la lógica, porque el despliegue del espíritu absoluto es despliegue que acontece en un devenir histórico. Así, "La unidad profunda del espíritu absoluto con el espíritu subjetivo y el espíritu objetivo, sitúan a la historia en el plano último de la realidad y de la unidad del todo" (Ellacuría 2007 536). Para Ellacuría, aquí residiría uno de los principales aportes de Hegel a la problematización de la historia y la metafísica, ya que confirmaría su planteamiento de la realidad histórica como el objeto de la filosofía.

En cuanto a Marx, lo relevante del encuentro, nos parece, es todo el aparataje crítico conceptual que el marxismo ofrece y que le permite fundamentar su búsqueda de una liberación histórica. Así, el diálogo zubiriano-marxista habría contribuido a planteamientos tales como el de praxis histórica, e ideología-ideologización. 
La discusión ellacuriana con el paradigma dialéctico, en sus versiones hegeliana y marxista, son fundamentales para la construcción de su propio paradigma, y este no es ajeno a Zubiri. Por ello, aun en su planteamiento de la "realidad histórica" Ellacuría continúa muy cercano a su maestro. Por esta razón disentimos de aquellos planteamientos que afirman un distanciamiento entre discípulo y maestro, como el de Ricardo Ribera, quien afirma: "Zubiri había defendido que el objeto de la filosofía debe ser la realidad. Ellacuría iniciará un cuidadoso distanciamiento o superación de su amigo y maestro, a partir de una serie de matizaciones" (Ribera 2013 36). Y es que, si bien Ellacuría realiza esas matizaciones señaladas por Ribera, ello no significa que esté buscando un distanciamiento ni una superación. Zubiri continuará en la base de todo el planteamiento ellacuriano, inclusive en aquellos aspectos que a finales de los años setenta fueron producto de su desplazamiento hacia lo político. Ellacuría señala que, aunque el planteamiento dialéctico explica bien el modo como acontecen ciertos procesos, estos pertenecen a un tipo específico de realidad, a saber, la realidad social; de ahí que Ellacuría sostenga que las herramientas conceptuales del paradigma dialéctico, especialmente de lectura marxista, operan solo en ciertos tipos de realidades con determinadas características históricas.

No haremos una descripción de la explicación ellacuriana sobre la dialéctica hegeliana ${ }^{3}$ (Ellacuría 2009), pues retomaremos solo aquellos elementos que, a nuestro juicio, son fundamentales para el desarrollo de nuestra propuesta. No cabe duda de que la dialéctica es fundamental para la propuesta de la realidad histórica como objeto último de la filosofía. Si bien Ellacuría discute ya con Hegel en el texto "El concepto de naturaleza en el materialismo dialéctico", de 1970, no es sino hasta fines de esa misma década que discutirá directamente, en los cuadernos que serán la base para su obra póstuma, con la dialéc-

3 Para un análisis detallado de la explicación ellacuriana de la dialéctica véase, "El concepto de naturaleza en el materialismo dialéctico", en Archivo Personal de Ignacio Ellacuría, carpeta 16, unidad de instalación c3, y "Hegel y el método dialéctico", en Cursos Universitarios. 
tica hegeliana. De ambos autores, Marx y Hegel, Ellacuría retoma la perspectiva de totalidad de la realidad que sirve de basamento para la comprensión de la "realidad histórica" como algo último y radical. Sin embargo, para Ellacuría, uno de los inconvenientes con la dialéctica hegeliana es la marcada dependencia del dinamismo propio de lo real a algo externo a la cosa, el principio de su dinamismo no estaría en sí mismo, sino en el despliegue de una razón lógica. De ello se deduce algo fundamental, y es que, debido a que la dialéctica hegeliana es un devenir de la razón, "le cabe una estricta negatividad" (Samour $2006210)$.

La razón, al envolver ese momento de negatividad, se ve en la necesidad de salir de sí misma, y es ese movimiento lo que constituye el devenir, dando lugar así a la idea hegeliana de la unidad de contrarios, en la cual estos son momentos de un proceso. Así, en ese movimiento está la negatividad y la afirmatividad, y en un tercer momento la superación de ambos. No obstante, no debe comprenderse ese "estar" como algo fijo, estático, sino como un "estar" dinámico; tampoco debe comprenderse el tercer momento como una especie de disolución de los momentos anteriores: estos continuarán dinámicamente, señala Ellacuría, en el tercer momento. De ahí que la dialéctica, en sus versiones hegeliana y marxista, repare tanto en el movimiento como lo único permanente en la realidad. En este sentido, Marx considera que "el capital no es una simple relación, sino un proceso en momentos distintos. Las cosas pueden presentar la apariencia de estar quietas, pero no es así 'en realidad'" (Ellacuría 2007 20). Esta afirmación tiene serias consecuencias en el pensamiento ellacuriano, no solo a nivel metafísico, sino también político; por ejemplo, en la idea de "ideología" e "ideologización". Para Ellacuría, la ideología, a pesar de poseer cierta ambigüedad, es necesaria para la convivencia social, comunitaria y personal; el problema aparece cuando esta ideología enmascara la realidad, la esconde y deforma con apariencia de verdad, esto es desarrollado después de Filosofía de la realidad histórica. En este sentido, Ellacuría nos dice: "Todo esto es plenamente hegeliano y en muchos de sus aspectos algo común a muchos filósofos. Las apariencias muestran y engañan sólo el que alcanza la esencia de la 
cosa, alcanza el todo de la cosa, se apodera de ella y supera la barrera de las apariencias" (Id. 21).

Ese apoderarse de la esencia y la totalidad de la cosa, que Hegel considera como la verdad y la totalidad de lo real, pasa por la negación (Ibíd.). Ellacuría sostiene que la negación en Hegel es una fuerza creadora y lugar de encuentro con la idea cristiana de la negación como fuente de vida. Es ese tránsito por la muerte, es decir, la negación, lo que es capaz de generar vida. Así, la negación no es solo momento fundamental de la dialéctica hegeliana, sino también del mensaje cristiano. Se trata de una negación que no genera fragmentariedad, sino que es principio de unidad, que "no es sólo diacrónica, sino también sincrónica; no es sólo procesual, sino también estructural" (Id. 22). Por ello, Ellacuría sostiene que lo específico de la dialéctica no está primariamente en la existencia de contrarios sino en la predominancia de la negación ${ }^{4}$, tanto en lo que la dialéctica tiene de movimiento como en la conformación de la unidad producto de dicho movimiento. De este modo, señala Ellacuría, la negación tiene un carácter de principialidad de lo real. Marx, según Ellacuría, al contrario de Hegel, no partirá de la idea de una razón universal o espíritu absoluto, sino que sostendrá que lo más radical de la realidad es algo, en términos zubirianos, radicalmente intramundano, a saber, las condiciones materiales para la realización de la vida. De esta manera, Marx fue quien llevó a sus últimas consecuencias el carácter histórico de la realidad (Samour 2006 182), de ahí que Ellacuría sostenga que en Marx asistimos a un modo de pensar y enfrentarse a la realidad desde un logos histórico, un logos vinculado estrechamente con sus condiciones materiales, las

\footnotetext{
4 Heidegger también considera, en una línea similar a la ellacuriana, que la negatividad es el rasgo fundamental, no solo de la dialéctica, sino de toda la metafísica hegeliana. Para Heidegger la negatividad es la determinación (Grundbestimmung) del proyecto originario hegeliano, el cual, para comprenderlo en términos ontohistóricos, debe considerarse en sus tres aspectos, a saber, lógica, fenomenológica y sistemáticamente. Véase, Heidegger, Martin, "La negatividad. Una confrontación con Hegel desde el planteo de la negatividad (1938/39, 1941), en, Hegel, Biblioteca Internacional Martin Heidegger, Buenos Aires, 2005, y Mejía Emmanuel, "La negatividad en Hegel y la kehre heideggeriana", en, ÉNDOXA: Series Filosóficas 20, Madrid (2005): 757-771.
} 
cuales lo condicionan en su forma de comprender y de habérselas con el mundo.

\section{La negatividad histórica}

Con Hegel, la negación acontece como principialidad de lo real; con Marx, ya no se trata de la negación como principialidad de lo real, al menos no primariamente, sino de la experiencia histórica de la negatividad. Ellacuría señala que el momento fundante del marxismo es la "vivencia" de la no-justicia, la no-verdad, la no-solidaridad, como algo estructural y configurador de toda una época histórica. De ahí que la ausencia de esos elementos sea lo que constituye, según Ellacuría, la negatividad histórica. La negatividad no alude solamente a cómo la dimensión sociopolítica y económica de un determinado momento histórico está configurada, sino a una nota de la realidad histórica misma. En "Función liberadora de la filosofía", de 1985, Ellacuría, recordando a Heidegger, plantea:

Heidegger pensaba (Was ist Metaphysik?) que era la nada la que fundamentaba la posibilidad del no $y$, en general, de la negatividad; por ello, quizá, en vez de preguntarse por qué hay más bien ente que nada, debería haberse preguntado por qué hay nada -no ser, no realidad, no verdad, etc.- en vez de ente (Ellacuría 2005 101).

La negatividad no es solo histórica: posee también cierto carácter metafísico. Y es que la nada, por la ideologización, acontece como una realidad, una realidad falsificada y negada. En el texto "Historización de los derechos humanos desde los pueblos oprimidos y las mayorías populares", de 1989, Ellacuría señala que la realidad es una realidad negada debido a que la realidad no acontece como debería acontecer, es decir, el dinamismo de la realidad, su dar de sí, es obstaculizado. La nada que subyace a dicha realidad negada, "Evidentemente no se trata de la nada absoluta, pero sí de una cierta presencia de ella, que trae consigo inexorablemente la necesidad de una acción negadora [...]" (Ibíd). Esa realidad negada no refiere solamente a un nivel so- 
ciopolítico, sino también, de algún modo, metafísico; además, y este es un elemento fundamental de su hermenéutica, esa realidad es negada por otra realidad, una realidad negadora. En este contexto, es la filosofía, como búsqueda de fundamentos últimos y totalizantes, la que puede hacer trascender esa nada con apariencia de realidad y desenmascarar su ausencia de fundamentos mediante la acción negadora. De este modo, para Ellacuría, la filosofía, primariamente, es metafísica; por ello, aunque el discurso y los planteamientos ellacurianos tomen un tinte más político a partir de finales de la década de los setenta hasta su trágica muerte, es la metafísica intramundana, en diálogo con Hegel y Marx fundamentalmente, la que posibilitará su planteamiento político.

El marxismo permite a Ellacuría llevar esa negatividad de un plano lógico-racional-Hegel- a un plano histórico, lo cual, a su vez, posibilita llevar esa misma negatividad a la dimensión política de la historia. Así, para Ellacuría, el materialismo histórico marxista se acerca mucho al planteamiento zubiriano, al comprender la realidad material desde su última aparición en forma histórica (Samour 2006 190). De ahí que la comprensión del ser en el materialismo histórico se encuentre estrechamente vinculada con la materia histórica; de esta manera la conciencia es comprendida desde el ser, y no el ser desde la conciencia (Ibíd.).

\subsection{Hermenéutica negativa}

La idea de negatividad en Ellacuría es fundamental y no solo refiere a una negatividad metafísica e histórica, de las cuales ya se ha dicho algo, sino también a una negatividad metodológica y a un modo de estar en el mundo. Ellacuría señala que de la nada con apariencia de realidad, característica de la ideologización, surge la necesidad de superarla a través de una acción negadora, y es aquí, en esta acción negadora, donde la negatividad como método se manifiesta (Ellacuría 2000a 188). En 1977, en un curso sobre ética, Ellacuría llama la atención sobre la necesidad que los planteamientos teóricos tengan un arraigo en las situaciones concretas. Al encontrarse esas situaciones atravesadas por la negatividad, el hacer humano debe adquirir un 
carácter de negación de la negación, que se manifiesta en esas situaciones. En este sentido, Ellacuría afirma: "Metodológicamente supone la puesta en marcha de un proceso que va creando afirmaciones, las cuales a su vez deben ser superadas. El dinamismo de la negación de la negación es fundamentalmente positivo y se apoya últimamente en la intolerancia del mal y de lo negativo (Ellacuría 2009 255)".

En Filosofía de la realidad histórica, al ir mostrando las tesis que lo conducen a la formulación de la "realidad histórica" como el objeto de la filosofía, Ellacuría señala algunos elementos para comprender este carácter metodológico de la negatividad. Al referirse a la negatividad en términos cristianos, que se manifiesta en el pecado estructural, señala que solamente a través de la negación de aquella negación que se da en la realidad histórica es posible superarla. Solo a través de esa negación que niega la negatividad, que se ha constatado en ese enfrentamiento con la realidad, es que se dará un paso positivo y creador (Ellacuría 2007 37). Ahora bien, este paso no debe ser una réplica de esa negatividad constatada, por lo que el lugar desde el que surgirá la acción negadora, que Ellacuría llama "positiva negación", no será la negación, sino la afirmación de aquello que la negatividad histórica está negando, es decir, si en el enfrentamiento con la realidad constatamos las manifestaciones de la nada como no-justica, no-verdad, no-ser, etc. La acción negadora partirá desde la afirmación de esas negaciones; por ello, ya no se trataría de partir de la no-justicia, sino de la justicia. Solo cuando la acción negadora acontece como una afirmación esta acción adquiere carácter superador y no aniquilador (Id. 38). En "Función liberadora de la filosofía", un texto de 1985, y que algunos autores consideran como producto del último desplazamiento ellacuriano, es decir, el tránsito de una filosofía política a una filosofía con claro énfasis liberador, la negatividad continúa presente como un elemento constitutivo de la filosofía. Según Ellacuría, la filosofía, en su función crítica, refiere a una negatividad crítica que sería la que posibilitaría trascender esa nada que acontece como negatividad en la ideologización. Dicha nada nos lleva, sostiene Ellacuría, inexorablemente, a una acción negadora, y será ella la que permita desenmascarar esa nada con apariencia de realidad, y en esa medida la acción negadora nos desvelará la realidad real posibilitando 
así su afirmación (Ellacuría 2005 101). La negatividad, además, no solo refiere a esa nada con apariencia de realidad que se transparenta en la negatividad histórica, refiere también a una actitud, a un "gesto", a un determinado modo de encontrase en el mundo del filósofo; ello debido a las exigencias que Ellacuría realiza a quienes se dediquen a la labor filosófica.

[A I]os filósofos (...) debe permitírseles llevar una existencia socrática, que muestra permanentemente las deficiencias en el saber y en el hacer. Y si no les permite llevar la vida filosófica de Sócrates, deben emprenderla por su cuenta hasta merecer la condenación o el ostracismo de su sociedad (Id. 59).

Para Ellacuría, la figura de Sócrates encarna esta negatividad, esta que ya no refiere solamente a algo frente al sujeto, sino a un gesto, a un modo fundamental de "encontrarse" en el mundo 5 . Sócrates, según Ellacuría, no está interesado solamente en el saber por saber, sino en que las cosas lleguen y puedan ser lo que realmente son; de ahí que ese saber buscado por Sócrates sea constitutivamente un saber crítico frente a su propio conocimiento y frente al conocimiento que los demás decían poseer (Ellacuría 2001b 117 118); es decir, frente al pensamiento hegemónico de su época, Sócrates no asumía una posición que afirmaba dicho pensamiento, sino la de un pensador que habitaba

5 Este encontrarse entonces, no solo refiere a las circunstancias concretas, sino también a un determinado modo de estar en ellas. Esas condiciones socio-históricas de las que habla Ellacuría no solo están relacionadas con el carácter de situado característico de la filosofía latinoamericana, sino también con la situación hermenéutica, concepto relevante para la hermenéutica heideggeriana. Para Heidegger, "Toda interpretación se despliega, en función de su ámbito de realidad y de su pretensión cognoscitiva, en el marco de las siguientes coordenadas; 1 ) un punto de mira, más o menos expresamente apropiado y fijado; 2) una subsiguiente dirección de la mirada, en la que se determina el 'como algo' según el cual se debe precomprender el objeto de la interpretación y el 'hacia dónde' debe ser interpretado ese mismo objeto; 3) un horizonte de la mirada delimitado por el punto de mira y por la dirección de la mirada, en cuyo interior se mueve la correspondiente pretensión de objetividad de toda interpretación". Heidegger, Martin, Interpretaciones fenomenológicas de Aristóteles. Indicación de la situación hermenéutica. Madrid: Trotta, 2002, 29-30. 
la negatividad, la sospecha, el ansia de liberación frente a todo lo que había sido impuesto. Además, Sócrates poseía un profundo interés y "amor" por la polis, de ahí que en su pensamiento sea transversal el servir a la polis; por ello se entiende su negativa a aceptar el ostracismo para salvar su vida, ya que solo dentro de la polis la vida tenía sentido. Dicho lo anterior, es claro que la negatividad no es solo algo externo al filósofo; la negatividad es un determinado modo de "encontrarse" que posibilita la toma de distancia y liberación del sometimiento a un determinado pensamiento. Esta negatividad se refiere a un "poner en duda" todo aquello que "se hace" aparecer como determinante para una sociedad: las leyes, las normas, la eticidad, las instituciones, etc. La negatividad se manifiesta en la capacidad que tiene el filósofo, según Ellacuría, de mostrar el carácter no absoluto y universal de eso que se ha mostrado como tal.

El ejercicio hermenéutico para Ellacuría, como ya se ha señalado, posee una clara orientación: la iluminación de la praxis política en esta situación de negatividad histórica-real de los grupos oprimidos, y alentar procesos de transformación de la negatividad histórica (Samour 2014 194). Esto es la finalidad del método de la historización de los conceptos $^{6}$ de Ellacuría. La historización de los conceptos refiere a las condiciones histórico-reales que posibilitan cierto tipo de conceptos, lo cual es una denuncia de una pretendida universalidad. En un artículo de 1976, "La historización del concepto de propiedad como principio de desideologización", Ellacuría realiza una breve descripción de lo que comprende como historizar los conceptos:

\footnotetext{
6 Véase "La historización del concepto de propiedad como principio de desideologización", en ECA, 335-336, UCA Editores, San Salvador, 1976; "La historización del bien común y los derechos humanos en una sociedad dividida", en E. Támez y S. Trinidad (eds.), Capitalismo: violencia y antivida, T. II, San José, Costa Rica: EDUCA, 1977; "La historización de los derechos humanos desde los pueblos oprimidos y las mayorías populares", en ECA, 502, UCA Editores, San Salvador, 1990. Los últimos dos artículos están compilados en Escritos filosóficos III, UCA Editores, San Salvador, 2001. El primero en Veinte años de historia en El Salvador (1969-1989), Tomo I, UCA Editores, San Salvador, 2005.
} 
Mostrar qué van dando de sí en una determinada realidad ciertos conceptos, es lo que se entiende aquí por historización. Por eso, la historización de los conceptos es principio de desideologización. En efecto, las ideologías dominantes viven de una falacia fundamental, la de dar como conceptos reales e históricos, como valores efectivos y operantes, como pautas de acción eficaces, unos conceptos o representaciones, unos valores y unas pautas de acción, que son abstractos y universales. Como abstractos y universales son admitidos por todos; aprovechándose de ello, se subsumen realidades que, en su efectividad histórica, son la negación de lo que dicen ser (Ellacuría 2005 591).

Para Ellacuría, es evidente que los conceptos no son independientes del devenir de las realidades históricas a las que refieren, y aun aquellos que aparecen como invariables a una supuesta naturaleza humana deberán ser desfundamentados (Herrera 1995 35), no solo para desenmascarar los intereses que dichos conceptos ocultan, sino también para develar aquellas condiciones históricas que posibilitan o imposibilitan lo que de verdad hay en dichos conceptos (Ibíd.). En un artículo de 1989, el año de su asesinato, titulado, "Historización de los derechos humanos desde los pueblos oprimidos y las mayorías populares", Ellacuría nos ofrece una descripción más acabada de su método de historización de los conceptos. En ese artículo señala que el método de la historización exige historizar desde lo que define más negativamente la situación de la mayoría.

Se trata de buscar la raíz más profunda de esa negatividad, sin desconocer que la negatividad real, por muy real que sea, no demuestra toda su negatividad más que en contrapunto con alguna positividad más o menos atemáticamente apreciada... La negación debe verse desde dos polos: desde la realidad negada, que no puede llegar a ser aquello que podría y debería ser precisamente porque se lo impiden (se da efectivamente un dinamismo real de superación, que está siendo obstaculizado, sea cual fuera el origen de la verdad-justicia-justeza de ese dinamismo), y desde 
la realidad negadora, cualquiera que esta sea (personal, grupal, clasista, estructural, institucional, etc.) (Ellacuría 2001a 439).

\subsection{El lugar-que-da-verdad como criterio de validez hermenéutica}

Ahora bien, un elemento común de la hermenéutica, en sus diversas expresiones, consiste en la pregunta por la interpretación correcta, es decir, la pregunta por la validez y corrección de lo interpretado dentro del contexto histórico en el que tales preguntas se plantean, cuestión que se agudiza más por las críticas realizadas por Nietzsche, para quien lo que debe reconocerse es que el objeto existe como un objeto ya interpretado, no ahondaremos en esta discusión, ya que escapa a las pretensiones de nuestro trabajo; sin embargo, es pertinente señalar que, dentro de la hermenéutica ellacuriana, el carácter de verdad de lo interpretado obedece a aquello que Ellacuría llama el "lugar-que-da-verdad". Ellacuría parte de que el ser humano está im-plantado en el mundo (Nicolás 2016), y esa im-plantación es de carácter histórico-real. Ello, según Ellacuría, significaría que estamos en el mundo no de cualquier manera, sino decantados hacia ciertas situaciones y posicionamientos, es decir, se puede estar como opresor o como oprimido (Id. 6), por ello, el filósofo debe tomar partido, debe posicionarse frente a esa negatividad histórica haciendo eco de una exigencia ética, de ahí que el punto de partida de la reflexión ellacuriana sea la "opción preferencial por lo pobres" (Ellacuría 2000b). Los pobres -quienes son los oprimidos y dominados y constituyen la periferia, los márgenes de la historia- se convierten de esta manera no solo en objeto de reflexión, sino en lugar de experiencia. Los pobres se convierten, entonces, en lugar metafísico y epistemológico, metafísico porque Ellacuría convierte:

...lo marginal en criterio y baremo para medir y valorar la realidad social... con esta propuesta Ellacuría está buscando otro modo de pensar-actuar diferente desde su raíz y su motivación, por lo que puede interpretarse como una propuesta de transformación de la metafísica (Nicolás 2016 7). 
Epistemológico, porque la consideración de los pobres como lugar posibilita cierto tipo de experiencias que trasparentan ciertas dimensiones de la humanidad, dimensiones imposibles de conocer y experimentar de otra manera ( $(\mathrm{bí} d)$. Así, los pobres devienen en el lugar-que-da-verdad. En "Función liberadora de la filosofía", Ellacuría señala que la única manera de ser verdaderos en la tarea liberadora es situándose en el lugar que da verdad histórica. En los márgenes de la historia, señala el filósofo mártir, no hay encubrimiento y la negatividad histórica aparece sin distorsiones.

La historia así entendida no es que sea maestra de la vida, sino que es maestra de la verdad. El momento opcional, que busca ese lugar-que-da-verdad y que hace verdad, no debe ser ciego, sino iluminado; iluminado, en un primer paso, por una valoración ética que hace de la justicia y de la libertad, mejor dicho de la no-justicia y de la no-libertad que se dan en nuestra situación como hecho primarios, un punto de referencia esencial, e iluminado, en un segundo paso, por la valoración teórica que ve en la injusticia y en al no-libertad una de las representaciones fundamentales de la verdad (Ellacuría 2005 115).

\section{Conclusiones}

Quisiera terminar apuntando que nuestra pretensión ha sido proponer un nuevo modo de aproximación y comprensión de la obra ellacuriana. Nos parece que la negatividad es un concepto operativo transversal en el pensamiento de Ellacuría desde la década de los setenta, y, si bien posee una impronta hegeliana y marxista importante, esa negatividad-afirmatividad-superadora tiene en la filosofía ellacuriana elementos cristianos que son fundamentales para su comprensión. Uno de ellos es la experiencia pascual de la resurrección y la comprensión del profetismo en el plano de la negación y la negatividad (Arredondo 2013 58). De esta manera, la negatividad permite a Ellacuría un nuevo modo de acceso a ciertos lugares del cristianismo y, además, una nueva comprensión de la historia. La historización de esa negatividad es una 
de los aspectos relevantes de la filosofía de Ellacuría, por lo que debe comprenderse como un concepto operativo estrechamente vinculado a una determinada vivencia histórica y, por lo tanto, la respuesta a ella no solo será teórica, sino, y esto es lo más radical en Ellacuría, histórica-fáctica-concreta, porque al final la búsqueda ellacuriana es la transformación radical de esa realidad negada.

Nuestro trabajo, si bien ha retomado algunos elementos teológicos, se centró en la dimensión filosófica de la negatividad. Se podría pensar que, dado que el objeto de interpretación de la hermenéutica ellacuriana es la negatividad histórica, ella debería ser una hermenéutica de la negatividad; sin embargo, consideramos que el ejercicio hermenéutico no solo considera a la negatividad histórica como objeto a interpretar, sino que el ejercicio mismo es negativo, y el intérprete mismo asume también un modo negativo de encontrase en esa negatividad histórica. De tal manera que la negatividad describe una nota constitutiva del objeto a interpretar, al agente de interpretación que se encuentra de un modo particular en esa negatividad histórica, y al modo como ese intérprete realiza el ejercicio hermenéutico. Por ello, consideramos más apropiada la comprensión de su hermenéutica como una hermenéutica negativa y no como una hermenéutica de la negatividad.

\section{Bibliografía}

Alvarenga, Luis. "Una teoría crítica para El Salvador. Negatividad, historización y praxis liberadora en Ignacio Ellacuría". ECA 68/732. San Salvador: UCA Editores (2013).

Arredondo, David. "Injusticia y negatividad en Ignacio Ellacuría". ECA 68/732. San Salvador: UCA Editores (2013).

Ellacuría, Ignacio. Filosofía de la realidad histórica. San Salvador: UCA Editores, 2007.

Ellacuría, Ignacio. "Historización de los derechos humanos desde los pueblos oprimidos y las mayorías populares", en: Escritos Filosóficos III. San Salvador, UCA Editores, 2001a. Publicado también en ECA, 502, 589-596, 1990, y en LUMEN 39, 9-19, 1990. 
Ellacuría Ignacio. "Hacia una fundamentación del método teológico latinoamericano", en Escritos Teológicos I. San Salvador: UCA Editores, 2000a. Artículo publicado en ECA, 322-323, 409-425, 1975 y compilado en Escritos Teológicos I.

Ellacuría Ignacio. "El mal común y los derechos humanos", en Escritos filosóficos III. San Salvador: UCA Editores, 2001a. Apuntes de clase del curso de derechos humanos impartido por Ellacuría de marzo a junio de 1989 en la UCA de El Salvador.

Ellacuría, Ignacio. "Hegel y el método dialéctico", en Cursos universitarios. San Salvador: UCA Editores, 2009.

Ellacuría, Ignacio. "Visión sociológica del hombre latinoamericano" de 1968, en Archivo personal de Ignacio Ellacuría, carpeta 1, unidad de instalación C. 2.

Ellacuría Ignacio. "El concepto de naturaleza en el materialismo dialéctico" de 1970c, en: Archivo personal de Ignacio Ellacuría, carpeta 16, unidad de instalación C. 3.

Ellacuría Ignacio. "Función liberadora de la filosofía", en Escritos Políticos I. San salvador: UCA Editores, 2005. Artículo publicado en ECA, 435-436, UCA Editores, 1985.

Ellacuría Ignacio. "Curso de ética", en Cursos universitarios. San Salvador: UCA Editores, 2009.

Ellacuría Ignacio. "Filosofía, ¿para qué?", en: Escritos filosóficos III. San Salvador: UCA Editores, 2001b.

Ellacuría, Ignacio. "La historización del concepto de propiedad como principio de desideologización". ECA. San Salvador: UCA Editores, 1976. 335-336.

Ellacuría Ignacio. "La opción preferencial or los pobres", en Escritos Teológicos II. San Salvador: UCA Editores, 2000b. Artículo publicado en Vida Nueva 1258-1259, 35-36, 1980-1981; y reproducido en Diakonía 17, 57-59, 1981.

De Lara, Francisco. "Interpretación, historicidad y negación. Sobre el lugar político de la filosofía en Heidegger y Adorno". ALEA 12. Rio de Janeiro (2014).

Flores García, Víctor. El lugar que da verdad: la filosofía de la realidad histórica de Ignacio Ellacuría. México D.F.: Editorial Universidad Iberoamericana, 1997.

Fornet-Betancourt, Raúl. "Filosofía y teología. Apuntes para la revisión intercultural de una distinción dudosa", en Filosofía y espiritualidad en diálogo. Aachen: Wissenschaftsverlag Mainz, 2016.

Heidegger, Martin. Interpretaciones fenomenológicas de Aristóteles. Indicación de la situación hermenéutica. Madrid: Trotta, 2002. 
Heidegger, Martin. "La negatividad. Una confrontación con Hegel desde el planteo de la negatividad (1938/39, 1941). En: Hegel. Buenos Aires: Biblioteca Internacional Martin Heidegger, 2005.

Herrera, Alfredo Sajid. "Aproximación al método de historización de Ignacio Ellacuría", en Para una filosofía liberadora. Primer encuentro mesoamericano de filosofía. San Salvador: UCA Editores, 1995.

Lasalle-Klein, Robert. "Rahner's Contribution to Two Aspects of Ignacio Ellacuría's Latin American Approach to Fundamental Theology", en Ignacio Ellacuría: el vigésimo quinto aniversario, Rodolfo Cardenal, S.J., and Martin Maier, S.J. San Salvador: UCA Editores, 2014.

Lasalle-Klein, Robert. "La historización de la filosofía de la religión de Karl Rahner en Ignacio Ellacuría y Xavier Zubiri", en Historia, ética y ciencia. El impulso crítico de la filosofía de Zubiri. Granada: Editorial Comares, 2007.

Luengo Rubalcaba, Jorge. Zubiri y Kant. Bilbao: Editorial Universidad de Deusto, 1998.

Llevadot, Laura. "Negatividad: La figura de Sócrates en la obra de Kierkegaard". Contraste. Revista Internacional de Filosofía XIV. Málaga: Universidad de Málaga (2008).

Maier, Martin. "La influencia de Karl Rahner en la teología de Ignacio Ellacuría II". Revista Latinoamericana de Teología. San Salvador: UCA Editores (1998).

Maier, Martin. "La influencia de Karl Rahner en la teología de Ignacio Ellacuría". Revista Latinoamericana de Teología 13/39. San Salvador: UCA Editores (1996).

Mejía Emmanuel. "La negatividad en Hegel y la kehre heideggeriana". ÉNDOXA: Series Filosóficas 20. Madrid: Facultad de Filosofía de la Universidad Nacional de Educación a distancia (2005).

Metz, Johan Baptist. La fe en la historia y la sociedad. Madrid: Ediciones Cristiandad, S.L., 1979.

Nicolás, Juan Antonio. "Zubiri urbanizado: la filosofía de la experiencia de I. Ellacuría". ARBOR 192/780. España: Consejo Superior de Investigaciones Científicas (2016).

Rahner, Karl. Espíritu en el mundo. Metafísica del conocimiento finito según Santo Tomás de Aquino. Barcelona: Editorial Herder, 1963.

Rahner, Karl. Oyente de la palabra. Fundamentos para una filosofía de la religión. Barcelona: Herder Editorial, 1976. 
Ribera Ricardo. "Ignacio Ellacuría y la dialéctica". ECA 60/732. San Salvador: UCA Editores (2013).

Samour Héctor. "Posmodernidad y filosofía de la liberación". ECA 69, San Salvador: UCA Editores (2014): 737-738.

Samour Héctor. "El concepto de 'mal común' y la crítica a la civilización del capital en Ignacio Ellacuría". ECA 68/732. San Salvador: UCA Editores (2013).

Samour, Héctor. Voluntad de liberación. El pensamiento filosófico de Ignacio Ellacuría. San Salvador: UCA Editores, 2006.

Samour, Héctor. "El diálogo de Ellacuría con Marx y el marxismo". Revista Realidad 140. San Salvador: UCA Editores (2014).

Schickendantz, Carlos. "El método antropológico-trascendental de Karl Rahner como hermenéutica teológica del mundo y la praxis". Teología y Vida XLV. Santiago de Chile: Pontificia Universidad Católica de Chile (2004).

Zuchel, Lorena. "Ignacio Ellacuría, filósofo cristiano. Reflexión-teológica sobre la inexorable acción de cargar con la realidad". Teología y Vida 55/4, Santiago de Chile: Pontifica Universidad Católica de Chile (2014).

Zuchel, Lorena. "Ignacio Ellacuría y la acerca de la 'filosofia ¿para qué?'". Annales XXXVI/1. Lublin-Polonia: Universitatis Marie Curie-Sklodowska (2011).

Tamayo, Juan José y Alvarenga Luis, (eds). Ignacio Ellacuría. Utopía y teoría crítica. Valencia: Tirant humanidades, 2014. 